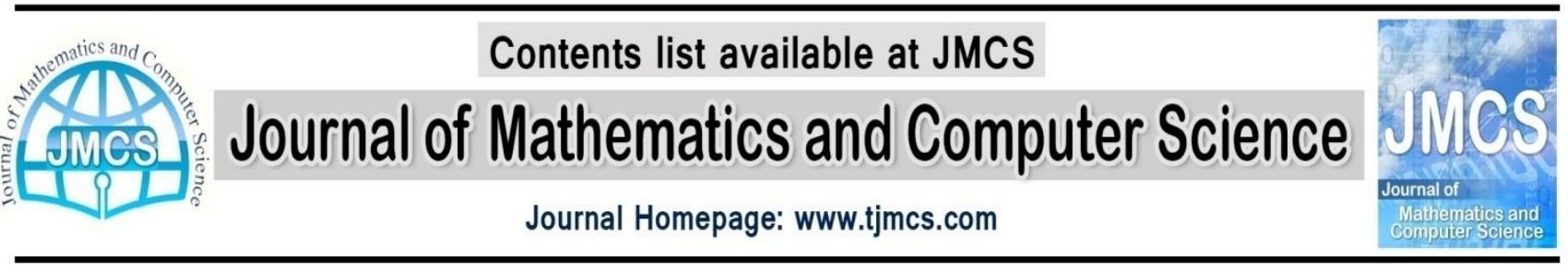

\title{
A Best Proximity Point Theorem in Metric Spaces with Generalized Distance
}

\author{
Mehdi Omidvari ${ }^{1}$, S. Mansour Vaezpour ${ }^{2}$ \\ ${ }^{1}$ Department of Mathematics, Science and Research Branch, Islamic Azad University, Tehran, Iran, \\ ${ }^{2}$ Department of Mathematics and Computer Science, Amirkabir University of Technology, Hafez Ave., \\ P. O. Box 15914, Tehran, Iran, \\ ${ }^{1}$ mehdi.omidvari@gmail.com, ${ }^{2}$ vaez@aut.ac.ir
}

\begin{abstract}
In this paper at first, we define the weak P-property with respect to a $\tau$-distance such as $p$. Then we state a best proximity point theorem in a complete metric space with generalized distance such that it is an extension of previous research.
\end{abstract}

Keywords: weak P-property, best proximity point, $\tau$-distance, weakly contractive mapping, altering distance functions.

\section{Introduction}

The best proximity point is a interesting topic in best proximity theory. Let $A, B$ be two non-empty subsets of a metric space $(X, d)$ and $T: A \rightarrow B$. A solution $x$, for the equation $d(x, T x)=d(A, B)$ is called a best proximity point of $T$. If $d(x, T x)=0$ then $x$ is called a fixed point of $T$ [15]. The existence and convergence of best proximity points has generalized by several authors such as Jleli and Samet [3], Prolla [4], Reich [5], Sadiq Basha [7,8], Sehgal and Singh [10,11], Vertivel, Veermani and Bhattacharyya[13] in many directions. On the other hand Suzuki [12] introduced the concept of $\tau$ distance on a metric space. Many fixed point theorems extended for various contractive mappings with respect to a $\tau$-distance. In this paper, by using the concept of $\tau$-distance, we prove a best proximity point theorem. Our results are extension of a best proximity point theorem in metric spaces.

\section{Preliminary}

Let $A, B$ be two non-empty subsets of a metric space $(X, d)$. The following notations will be used throughout this paper:

$d(y, A):=\inf \{d(x, y): x \in A\}$,

$d(A, B):=\inf \{d(x, y): x \in A, y \in B\}$,

$A_{0}:=\{x \in A: d(x, y)=d(A, B)$ for some $y \in B\}$,

\footnotetext{
${ }^{2}$ Corresponding author
} 
$B_{0}:=\{x \in B: d(x, y)=d(A, B)$ for some $x \in A\}$.

We recall that $x \in A$ is a best proximity point of the mapping $T: A \rightarrow B$ if $d(x, T x)=d(A, B)$. It can be observed that a best proximity reduces to a fixed point if the underlying mapping is a selfmapping.

Definition 2.1.[9] Let $(A, B)$ be a pair of non-empty subsets of a metric space $X$ with $A \neq \emptyset$. Then the pair $(A, B)$ is said to have the $\mathrm{P}$-property if and only if

where $x_{1}, x_{2} \in A_{0}$ and $y_{1}, y_{2} \in B_{0}$.

$$
\left.\begin{array}{l}
d\left(x_{1}, y_{1}\right)=d(A, B) \\
d\left(x_{2}, y_{2}\right)=d(A, B)
\end{array}\right\} \Rightarrow d\left(x_{1}, x_{2}\right)=d\left(y_{1}, y_{2}\right)
$$

It is clear that, for any nonempty subset $A$ of $X$, the pair $(A, A)$ has the P-property.

Rhoades [6] introduced a class of contractive mappings called weakly contractive mapping. Harjani and Sadarangani [1] generalized the concept of the weakly contractive mappings in partially ordered metric spaces.

Definition 2.2.[2] A function $\psi:[0, \infty) \rightarrow[0, \infty)$ is said to be an altering distance function if it satisfies the following conditions:

(i) $\quad \psi$ is continuous and non-decreasing.

(ii) $\psi(t)=0$ if and only if $t=0$.

Definition 2.3.[6] Let $(X, d)$ be a metric space. $T: X \rightarrow X$ is weakly contractive if

$$
d(T x, T y) \leq d(x, y)-\phi(d(x, y)), \quad \forall x, y \in X
$$

Where $\phi$ is a altering distance function.

Suzuki [12] introduced the concept of $\tau$-distance on a metric space.

Definition 2.4.[12] Let $X$ be a metric space with metric $d$. A function $p: X \times X \rightarrow[0, \infty)$ is called $\tau$ distance on $X$ if there exist a function $\eta: X \times[0, \infty) \rightarrow[0, \infty)$ such that the following are satisfied:

( $\tau 1) ~ p(x, z) \leq p(x, y)+p(y, z) \quad \forall x, y, z \in X$

( $\tau 2) \eta(x, 0)=0$ and $\eta(x, t) \geq t$ for all $x \in X$ and $t \in[0, \infty)$, and $\eta$ is concave and continuous in it's second variable.

( $\tau 3) \lim _{n} x_{n}=x$ and $\lim _{n} \sup \left\{\eta\left(z_{n}, p\left(z_{n}, x_{m}\right)\right): m \geq n\right\}=0$ imply $p(w, x) \leq \liminf _{n} p\left(w, x_{n}\right)$ for all $w \in X$

( $\tau 4) \lim _{n} \sup \left\{p\left(x_{n}, y_{m}\right): m \geq n\right\}=0$ and $\lim _{n} \eta\left(x_{n}, t_{n}\right)=0$ imply $\lim _{n} \eta\left(y_{n}, t_{n}\right)=0$;

( $\tau 5) \lim _{n} \eta\left(z_{n}, p\left(z_{n}, x_{n}\right)\right)=0$ and $\lim _{n} \eta\left(z_{n}, p\left(z_{n}, y_{n}\right)\right)=0$ imply $\lim _{n} d\left(x_{n}, y_{n}\right)=0$.

Remark 2.5.[12] It can be replaced ( $\tau 2)$ by the following $(\tau 2)^{\prime}$.

$(\tau 2)^{\prime} \inf \{\eta(x, t): t>0\}=0$ for all $x \in X$ and $\eta$ is non-decreasing in it's second variable.

Remark 2.6. If $(X, d)$ is a metric space, then the metric $\mathrm{d}$ is a $\tau$-distance on $X$.

In the following examples, we define $\eta: X \times[0, \infty) \rightarrow[0, \infty)$ by $\eta(x, t)=t$, for all $x \in X$ and $t \in[0, \infty)$. It is easy to see that $p$ is a $\tau$-distance on metric space $X$.

Example 2.7. Let $(X, d)$ be a metric space and $c$ be a positive real number. Then $p: X \times X \rightarrow[0, \infty)$ by $p(x, y)=c$ for $x, y \in X$ is a $\tau$-distance on $X$.

Example 2.8. Let $(X,\|\|$.$) be a normed space. p: X \times X \rightarrow[0, \infty)$ by $p(x, y)=\|x\|+\|y\|$ for $x, y \in X$ is a $\tau$-distance on $X$.

Example 2.9. Let $(X,\|\|$.$) be a normed space. p: X \times X \rightarrow[0, \infty)$ by $p(x, y)=\|y\|$ for $x, y \in X$ is a $\tau$ distance on $X$. 
Definition 2.10.[12] Let $(X, d)$ be a metric space and $p$ be a $\tau$-distance on $X$. A sequence $\left\{x_{n}\right\}$ in $X$ is a $p$ Cauchy if there exists a function $\eta: X \times[0, \infty) \rightarrow[0, \infty)$ satisfying $(\tau 2)-(\tau 5)$ and a sequence $\left\{z_{n}\right\}$ in $X$ such that $\lim _{n} \sup \left\{\eta\left(z_{n}, p\left(z_{n}, x_{m}\right)\right): m \geq n\right\}=0$.

The following lemmas are essential for the next sections.

Lemma 2.11.[12] Let $(X, d)$ be a metric space and $p$ be a $\tau$-distance on $X$. If $\left\{x_{n}\right\}$ is a $p$-Cauchy sequence, then it is a Cauchy sequence. Moreover if $\left\{y_{n}\right\}$ is a sequence satisfying $\lim _{n} \sup \left\{p\left(x_{n}, y_{m}\right): m \geq n\right\}=0$, then $\left\{y_{n}\right\}$ is also $p$-Cauchy sequence and $\lim _{n} d\left(x_{n}, y_{n}\right)=0$.

Lemma 2.12.[12] Let $(X, d)$ be a metric space and $p$ be a $\tau$-distance on $X$. If $\left\{x_{n}\right\}$ in $X$ satisfies $\lim _{n} p\left(z, x_{n}\right)=0$ for some $z \in X$, then $\left\{x_{n}\right\}$ is a $p$-Cauchy sequence. Moreover if $\left\{y_{n}\right\}$ in $X$ also satisfies $\lim _{n} p\left(z, y_{n}\right)=0$, then $\lim _{n} d\left(x_{n}, y_{n}\right)=0$. In particular, for $x, y, z \in X, p(z, x)=0$ and $p(z, y)=0$ imply $x=y$.

Lemma 2.13.[12] Let $(X, d)$ be a metric space and $p$ be a $\tau$-distance on $X$. If $\left\{x_{n}\right\}$ in $X$ satisfies $\lim _{n} \sup \left\{p\left(x_{n}, x_{m}\right): m \geq n\right\}=0$, then $\left\{x_{n}\right\}$ is a $p$-Cauchy sequence. Moreover if $\left\{y_{n}\right\}$ in $X$ satisfies $\lim _{n} p\left(x_{n}, y_{n}\right)=0$, then $\left\{y_{n}\right\}$ is also $p$-Cauchy sequence and $\lim _{n} d\left(x_{n}, y_{n}\right)=0$.

The next result is an immediate consequence of the Lemma 2.11 and Lemma 2.13.

Corollary 2.14. Let $(X, d)$ be a metric space and $p$ be a $\tau$-distance on $X$. If a sequence $\left\{x_{n}\right\}$ in $X$ satisfies $\lim _{n} \sup \left\{p\left(x_{n}, x_{m}\right): m \geq n\right\}=0$, then $\left\{x_{n}\right\}$ is a Cauchy sequence.

\section{Main results}

Inspire of Sankar Raj[9] and Zhang and others[14], we define the weak P-property with respect to a $\tau$-distance as follows:

Definition 3.1. Let $(A, B)$ be a pair of non-empty subsets of a metric space $(X, d)$ with $A_{0} \neq \emptyset$. Also let $p$ be a $\tau$-distance on $X$. Then the pair $(A, B)$ is said to have the weak P-property with respect to $p$ if and only if

where $x_{1}, x_{2} \in A_{0}$ and $y_{1}, y_{2} \in B_{0}$.

$$
\left.\begin{array}{l}
d\left(x_{1}, y_{1}\right)=d(A, B) \\
d\left(x_{2}, y_{2}\right)=d(A, B)
\end{array}\right\} \Rightarrow p\left(x_{1}, x_{2}\right) \leq p\left(y_{1}, y_{2}\right)
$$

It is clear that, for any nonempty subset $A$ of $X$, the pair $(A, A)$ has the weak P-property with respect to $p$.

Remark 3.2. If $p=d$ then $(A, B)$ is said to have the weak $P$-property where $A \neq \emptyset$. (See [14])

It is easy to see that if $(A, B)$ has the $P$-property then $(A, B)$ has the weak $P$-property.

Example 3.3. Let $X=\mathbb{R}^{2}$ with the usual metric and $p_{1}, p_{2}$ be two $\tau$-distances that defined in Example 2.8 and Example 2.9, respectively. Consider,

$A=\left\{(a, b) \in \mathbb{R}^{2} \mid a=0,2 \leq b \leq 3\right\}$,

$B=\left\{(a, b) \in \mathbb{R}^{2} \mid a=1, b \leq 1\right\} \cup\left\{(a, b) \in \mathbb{R}^{2} \mid a=1, b \geq 4\right\}$.

Then $(A, B)$ has the weak $P$-property with respect to $p_{1}$ and has not the weak $P$-property with respect to $p_{2}$.

By the definition of $A, B$ we obtain,

$$
d((0,2),(1,1))=d((0,3),(1,4))=d(A, B)=\sqrt{2}
$$

where $(0,2),(0,3) \in A_{0}$ and $(1,1),(1,4) \in B_{0}$. We have,

$\mathrm{p}_{1}((0,2),(0,3))=5$ and $\mathrm{p}_{1}((1,1),(1,4))=\sqrt{2}+\sqrt{17}$,

$\mathrm{p}_{1}((0,3),(0,2))=5$ and $\mathrm{p}_{1}((1,4),(1,1))=\sqrt{17}+\sqrt{2}$.

Therefore $(\mathrm{A}, \mathrm{B})$ has the weak P-property with respect to $p_{1}$. On the other hand, we have $\mathrm{p}_{2}((0,3),(0,2))=2$ and $\mathrm{p}_{2}((1,4),(1,1))=\sqrt{2}$. 
This implies that $(A, B)$ has not the weak $P$-property with respect to $p_{2}$.

Sankar Raj[9] stated a best proximity point theorem for weakly contractive non-self mappings in metric spaces. The following Theorem is an extension of his results in a metric spaces with generalized distance.

Theorem 3.4. Let $A$ and $B$ be non-empty closed subsets of the metric space $(X, d)$ such that $A_{0} \neq \emptyset$. Let $p$ be a $\tau$-distance on $X$ and $T: A \rightarrow B$ satisfies the following conditions:

(a) $T\left(A_{0}\right) \subseteq B_{0}$ and $(A, B)$ has the has the weak $P$-property with respect to $p$.

(b) $T$ is a continuous function on $A$ such that

$$
\psi(p(T x, T y)) \leq \psi(p(x, y))-\phi(p(x, y)), \forall x, y \in A
$$

where $\psi$ is an altering distance function and $\phi:[0, \infty) \rightarrow[0, \infty)$ is non-decreasing function also $\phi(t)=0$ if and only if $t=0$.

Then $T$ has a best proximity point in $A$. Moreover, if $d(x, T x)=d\left(x^{*}, T x^{*}\right)=d(A, B)$ for some $x, x^{*} \in$ $A$, then $p\left(x, x^{*}\right)=0$.

Proof. Choose $x_{0} \in A_{0}$. Since $T x_{0} \in T\left(A_{0}\right) \subseteq B_{0}$, there exists $x_{1} \in A_{0}$ such that $d\left(x_{1}, T x_{0}\right)=d(A, B)$. Again, $T x_{1} \in T\left(A_{0}\right) \subseteq B_{0}$, there exists $x_{2} \in A_{0}$ such that $d\left(x_{2}, T x_{1}\right)=d(A, B)$. Continuing this process, we can find a sequence $\left\{x_{n}\right\}$ in $A_{0}$ such that

$$
d\left(x_{n+1}, T x_{n}\right)=d(A, B), \quad \forall n \in \mathbb{N} \cup\{0\} .
$$

$(A, B)$ satisfies the weak $P$-property with respect to $p$, therefore from (1) we obtain,

$$
p\left(x_{n}, x_{n+1}\right) \leq p\left(T x_{n-1}, T x_{n}\right), \quad \forall n \in \mathbb{N} \text {. }
$$

We will prove that the sequence $\left\{x_{n}\right\}$ is convergent in $A_{0}$. Since $\psi$ is non-decreasing function we receive that

$$
\psi\left(p\left(x_{n}, x_{n+1}\right)\right) \leq \psi\left(p\left(T x_{n-1}, T x_{n}\right)\right), \quad \forall n \in \mathbb{N} .
$$

Also by the definition of $T$, we have

$$
\psi\left(p\left(T x_{n-1}, T x_{n}\right) \leq \psi\left(p\left(x_{n-1}, x_{n}\right)\right)-\phi\left(p\left(x_{n-1}, x_{n}\right)\right), \quad \forall n \in \mathbb{N} .\right.
$$

From (3) and (4), we receive that

$$
\begin{aligned}
\psi\left(p\left(x_{n}, x_{n+1}\right)\right) & \leq \psi\left(p\left(T x_{n-1}, T x_{n}\right)\right)-\phi\left(p\left(x_{n-1}, x_{n}\right)\right) \\
& \leq \psi\left(p\left(x_{n-1}, x_{n}\right)\right)-\phi\left(p\left(x_{n-1}, x_{n}\right)\right) \\
& \leq \psi\left(p\left(x_{n-1}, x_{n}\right)\right),
\end{aligned}
$$

for all $n \in \mathbb{N}$. Since $\psi$ is non-decreasing function, we have

$$
p\left(x_{n}, x_{n+1}\right) \leq p\left(x_{n-1}, x_{n}\right), \quad \forall n \in \mathbb{N} .
$$

Therefore, the sequence $\left\{p\left(x_{n}, x_{n+1}\right)\right\}$ is monotone non-increasing and bounded. Hence there exists $r \geq 0$ such that

$$
\lim _{n \rightarrow \infty} p\left(x_{n}, x_{n+1}\right)=r \geq 0 .
$$

We claim that $r=0$. Suppose to the contrary, that $r>0$. From the inequality

we obtain

$$
\psi\left(p\left(x_{n}, x_{n+1}\right)\right) \leq \psi\left(p\left(x_{n-1}, x_{n}\right)\right)-\phi\left(p\left(x_{n-1}, x_{n}\right)\right) \leq \psi\left(p\left(x_{n-1}, x_{n}\right)\right),
$$

Since $0<r \leq p\left(x_{n}, x_{n+1}\right)$ and $\phi$ is non-decreasing function,

$$
\lim _{n \rightarrow \infty} \phi\left(p\left(x_{n-1}, x_{n}\right)\right)=0
$$

So,

$$
0<\phi(r) \leq \phi\left(p\left(x_{n}, x_{n+1}\right)\right)
$$

$$
0<\phi(r) \leq \lim _{n \rightarrow \infty} \phi\left(p\left(x_{n}, x_{n+1}\right)\right),
$$

which is a contradiction. Hence $\lim _{n \rightarrow \infty} p\left(x_{n}, x_{n+1}\right)=0$. Similarly we receive that $\lim _{n \rightarrow \infty} p\left(x_{n+1}, x_{n}\right)=0$.

Now we show that $\lim _{n \rightarrow \infty} p\left(x_{n}, x_{m}\right)=0$ for $m>n$. In contrary case, there exists $\epsilon>0$ and two subsequence $\left\{x_{m_{k}}\right\},\left\{x_{n_{k}}\right\}$ such that $m_{k}$ is smallest index for which $m_{k}>n_{k}>k, p\left(x_{n_{k}}, x_{m_{k}}\right) \geq \epsilon$. This means that 
So, by the triangle inequality and (5), we have

$$
p\left(x_{n_{k}}, x_{m_{k}-1}\right)<\epsilon
$$

Letting $k \rightarrow \infty$, we receive that

$$
\begin{aligned}
\epsilon & \leq p\left(x_{n_{k}}, x_{m_{k}}\right) \\
& \leq p\left(x_{n_{k}}, x_{m_{k}-1}\right)+p\left(x_{m_{k}-1}, x_{m_{k}}\right) \\
& <\epsilon+p\left(x_{m_{k}-1}, x_{m_{k}}\right) .
\end{aligned}
$$

By triangle inequality, we have

$$
\lim _{\mathrm{k} \rightarrow \infty} \mathrm{p}\left(\mathrm{x}_{\mathrm{n}_{\mathrm{k}}}, \mathrm{x}_{\mathrm{m}_{\mathrm{k}}}\right)=\epsilon \text {. }
$$

$$
\begin{aligned}
& \mathrm{p}\left(\mathrm{x}_{\mathrm{n}_{\mathrm{k}}}, \mathrm{x}_{\mathrm{m}_{\mathrm{k}}}\right) \leq \mathrm{p}\left(\mathrm{x}_{\mathrm{n}_{\mathrm{k}}}, \mathrm{x}_{\mathrm{n}_{\mathrm{k}}-1}\right)+\mathrm{p}\left(\mathrm{x}_{\mathrm{n}_{\mathrm{k}}-1}, \mathrm{x}_{\mathrm{m}_{\mathrm{k}}-1}\right)+\mathrm{p}\left(\mathrm{x}_{\mathrm{m}_{\mathrm{k}}-1}, \mathrm{x}_{\mathrm{m}_{\mathrm{k}}}\right), \\
& \mathrm{p}\left(\mathrm{x}_{\mathrm{n}_{\mathrm{k}}-1}, \mathrm{x}_{\mathrm{m}_{\mathrm{k}}-1}\right) \leq \mathrm{p}\left(\mathrm{x}_{\mathrm{n}_{\mathrm{k}}-1}, \mathrm{x}_{\mathrm{n}_{\mathrm{k}}}\right)+\mathrm{p}\left(\mathrm{x}_{\mathrm{n}_{\mathrm{k}}}, \mathrm{x}_{\mathrm{m}_{\mathrm{k}}}\right)+\mathrm{p}\left(\mathrm{x}_{\mathrm{m}_{\mathrm{k}}}, \mathrm{x}_{\mathrm{m}_{\mathrm{k}}-1}\right) .
\end{aligned}
$$

Letting $\mathrm{k} \rightarrow \infty$ in above two inequality and using (6), we get

So,

$$
\lim _{\mathrm{k} \rightarrow \infty} \mathrm{p}\left(\mathrm{x}_{\mathrm{n}_{\mathrm{k}}-1}, \mathrm{x}_{\mathrm{m}_{\mathrm{k}}-1}\right)=\epsilon \text {. }
$$

From continuity of $\psi$ in the above inequality, we obtain that

$$
\begin{aligned}
0<\psi(\epsilon) & \leq \psi\left(\mathrm{p}\left(\mathrm{x}_{\mathrm{n}_{\mathrm{k}}}, \mathrm{x}_{\mathrm{m}_{\mathrm{k}}}\right)\right) \\
& \leq \psi\left(\mathrm{p}\left(\mathrm{Tx}_{\mathrm{n}_{\mathrm{k}}-1}, \mathrm{Tx}_{\mathrm{m}_{\mathrm{k}}-1}\right)\right) \\
& \leq \psi\left(\mathrm{p}\left(\mathrm{x}_{\mathrm{n}_{\mathrm{k}}-1}, \mathrm{x}_{\mathrm{m}_{\mathrm{k}}-1}\right)\right)-\phi\left(\mathrm{p}\left(\mathrm{x}_{\mathrm{n}_{\mathrm{k}}-1}, \mathrm{x}_{\mathrm{m}_{\mathrm{k}}-1}\right)\right) \\
& \leq \psi\left(\mathrm{p}\left(\mathrm{x}_{\mathrm{n}_{\mathrm{k}}-1}, \mathrm{x}_{\mathrm{m}_{\mathrm{k}}-1}\right)\right) .
\end{aligned}
$$

$$
\lim _{\mathrm{k} \rightarrow \infty} \phi\left(\mathrm{p}\left(\mathrm{x}_{\mathrm{n}_{\mathrm{k}}-1}, \mathrm{x}_{\mathrm{m}_{\mathrm{k}}-1}\right)\right)=0 .
$$

From $\lim _{\mathrm{k} \rightarrow \infty} \mathrm{p}\left(\mathrm{x}_{\mathrm{n}_{\mathrm{k}}-1}, \mathrm{x}_{\mathrm{m}_{\mathrm{k}}-1}\right)=\epsilon$, we can find $\mathrm{k}_{0} \in \mathbb{N}$ such that for any $k \geq k_{0}$,

This implies that,

$$
\frac{\epsilon}{2} \leq p\left(x_{n_{k}-1}, x_{m_{k}-1}\right) \text {. }
$$

$$
0<\phi\left(\frac{\epsilon}{2}\right) \leq \phi\left(p\left(x_{n_{k}-1}, x_{m_{k}-1}\right)\right), \quad \forall k \geq k_{0}
$$

and this contradicts to (7). Thus $\lim _{n \rightarrow \infty} p\left(x_{n}, x_{m}\right)=0$ for $m>n$ and this implies that,

$$
\lim _{n} \sup \left\{p\left(x_{n}, x_{m}\right): m \geq n\right\}=0
$$

Therefore by Corollary 2.14, $\left\{\mathrm{x}_{\mathrm{n}}\right\}$ is a Cauchy sequence in $A$. Since $X$ is a complete metric space and $A$ is a closed subset of $X$, there exists $x \in A$ such that $\lim _{n \rightarrow \infty} x_{n}=x . T$ is continuous, therefore with letting $n \rightarrow \infty$ in (1), we obtain

Now let $x^{*} \in A$ such that

$$
d(x, T x)=d(A, B)
$$

$$
d\left(\mathrm{x}^{*}, \mathrm{Tx}^{*}\right)=\mathrm{d}(\mathrm{A}, \mathrm{B}) \text {. }
$$

We claim that $p\left(x, x^{*}\right)=0$. Suppose to the contrary, that $p\left(x, x^{*}\right)>0$. Hence $\phi\left(p\left(x, x^{*}\right)\right)>0$ and therefore by the definition of $\mathrm{T}, \psi$, we obtain that,

$$
\psi\left(\mathrm{p}\left(\mathrm{x}, \mathrm{x}^{*}\right)\right) \leq \psi\left(\mathrm{p}\left(\mathrm{Tx}, \mathrm{Tx}^{*}\right)\right) \leq \psi\left(\mathrm{p}\left(\mathrm{x}, \mathrm{x}^{*}\right)\right)-\phi\left(\mathrm{p}\left(\mathrm{x}, \mathrm{x}^{*}\right)\right) \leq \psi\left(\mathrm{p}\left(\mathrm{x}, \mathrm{x}^{*}\right)\right),
$$

which is a contradiction. Hence $p\left(x, x^{*}\right)=0$ and this completes the proof of the theorem.

The next result is an immediate consequence of the Theorem 3.4 by taking $\psi(t)=0$ for all $t \geq 0$.

Corollary 3.5. Let $A$ and $B$ be non-empty closed subsets of the metric space $(X, d)$ such that $A_{0} \neq \emptyset$. Let $p$ be a $\tau$-distance on $X$ and $T: A \rightarrow B$ satisfies the following conditions:

(a) $T\left(A_{0}\right) \subseteq B_{0}$ and $(A, B)$ has the has the weak $P$-property with respect to $p$.

(b) $T$ is a continuous function on $A$ such that

$$
p(T x, T y) \leq p(x, y)-\phi(p(x, y)), \quad \forall x, y \in A
$$


where $\phi:[0, \infty) \rightarrow[0, \infty)$ is non-decreasing function also $\phi(t)=0$ if and only if $t=0$. Then $T$ has a best proximity point in $A$. Moreover, if $d(x, T x)=d\left(x^{*}, T x^{*}\right)=d(A, B)$ for some $x, x^{*} \in$ $A$, then $p\left(x, x^{*}\right)=0$.

The following result is the special case of the Corollary 3.5, obtained by setting $p=d$.

Corollary 3.6.[9] Let $(A, B)$ be a pair of two nonempty, closed subsets of a complete metric space $X$ such that $A_{0}$ is non-empty. Let $T: A \rightarrow B$ be a weakly contractive mapping such that $T\left(A_{0}\right) \subseteq B_{0}$. Assume that the pair $(A, B)$ has the $P$-property. Then there exists a unique $x^{*}$ in A such that $d\left(x^{*}, T x^{*}\right)=d(A, B)$.

\section{References}

[1] J. Harjani, K. Sadarangani, Generalized contractions in partially ordered metric spaces and applications to ordinary differential equations, Nonlinear Anal. 72,(2010) 1188-1197.

[2] M.S. Khan, M. Swaleh, S.Sessa, Fixed point theorems by altering distances between the points, Bull. Austral. Math. Soc. 30 (1),(1984) 1-9.

[3] M. Jleli and B. Samet, Best proximity points for $\alpha-\psi$-proximal contractive type mappings and applications, Bulletin des Sciences Mathematiques, 2013.

[4] J.B. Prolla, Fixed point theorems for set valued mappings and existence of best approximations, Numer. Funct. Anal. Optim. 5 (1982-1983) 449-455.

[5] S. Reich, Approximate selections, best approximations, fixed points and invariant sets, J. Math. Anal. Appl. 62 (1978) 104-113.

[6] B.E. Rhoades, Some theorems on weakly contractive maps, Nonlinear Anal. TMA 47 (4) (2001) 2683-2693.

[7] S. Sadiq Basha, Best proximity point theorems generalizing the contraction principle, Nonlinear Anal. 74 (2011) 5844-5850.

[8] S. Sadiq Basha, Best proximity point theorems, Approximation Theory 163 (2011) 1772-1781.

[9] V. Sankar Raj, A best proximity point theorem for weakly contractive non-self-mappings, Nonlinear Anal. 74 (2011) 4804-4808.

[10] V.M. Sehgal, S.P. Singh, A generalization to multifunctions of Fan's best approximation theorem, Proc. Amer. Math. Soc. 102 (1988) 534-537.

[11] V.M. Sehgal, S.P. Singh, A theorem on best approximations, Numer. Funct. Anal. Optim. 10 (1989) 181-184.

[12] T. Suzuki, Generalized distance and existence theorems in complete metric spaces, J. Math. Anal. Appl. 253 (2001) 440-458.

[13] V. Vetrivel, P. Veeramani, P. Bhattacharyya, Some extensions of Fans best approximation theorem, Numer. Funct. Anal. Optim. 13 (1992) 397-402.

[14] J. Zhang, Y. Su, Q. Cheng, Q: A note on "A best proximity point theorem for Geraghtycontractions", Fixed Point Theory Appl. 2013, Article ID 99 (2013). 
[15] M. Akram, W. Shamaila, Fixed point results in partial metric spaces using generalized weak contractive conditions, The Journal of Mathematics and Computer Science, 12 (2014) 85-98. 